\title{
Do We Still Need Preoperative Autologous Blood Donation? - It Is High Time for a Reappraisal!
}

\author{
Markus M. Müller Erhard Seifried \\ Institut für Transfusionsmedizin und Immunhämatologie, Klinikum der Johann Wolfgang Goethe-Universität Frankfurt am Main, \\ DRK-Blutspendedienst Baden-Württemberg - Hessen gGmbH, Frankfurt/M., Germany
}

\section{Key Words}

Preoperative autologous blood donation · Autologous hemotherapy · Risk-benefit analysis

\section{Summary}

Preoperative autologous blood donation (PABD) can be an adequate solution to a patient's problem before nonurgent surgery if a high $(>10 \%)$ probability of perioperative blood transfusion exists in this individual case and, at the same time, pre-existing alloimmunization or a different ethnic background make it difficult to supply this patient with compatible red blood cell concentrates. In times of acute shortness of blood, when nonurgent surgery might be rescheduled and delayed, and in cases of extreme angst-ridden patients fearing homologous blood transfusion, PABD can be considered in rare individual cases as well. Nonetheless, in all these cases, the patient must be eligible for PABD, and the indication as well as potential contraindications have to weighted against each other in a thorough individual risk-benefit analysis. However, these are relatively rare cases. Apart from these and few other situations, PABD in our opinion should not be used because of high costs and logistic efforts, high wastage, considerable risks for the donor/patient on the one hand and miniscule benefits on the other hand. PABD cannot significantly contribute to the blood supply. PABD in error-free use, which is unrealistic, reduces the risk of transmission of known and unknown viral pathogens, but possibly not of bacteria. In real life situations, the residual risk for transmission of transfusion-relevant viruses such as HIV, HVC or HBV is not diminished by PABD. The same is true for clerical errors and $A B O$ incompatibility or acute hemolytic transfusion reactions due to a mix-up of products. PABD reduces the risk of (allo)immunization and therefore has its indication in special clinical situations. PABD on the other hand increases the risks for the donor at the time of donation and afterwards. Autologous blood products seem to have higher rates of bacterial contamination. The risk for the patient to receive any transfusion perioperatively is increased due to the lower hemoglobin levels at admission (iatrogenic anemia) as well as due to a wrongly more liberal transfusion strategy in autologous hemotherapy compared to transfusion of homologous blood. A significant number of patients, who would never receive any transfusion perioperatively at all, enter the transfusion chain due to PABD procedures, facing the risks of a blood donor as well as the risks of a transfusion recipient.
Schlüsselwörter

Präoperative Eigenblutspende · Autologe Hämotherapie . Nutzen-Risiko-Analyse

\section{Zusammenfassung}

Die präoperative autologe Blutspende (PABD) (= Eigenblutspende) kann in Einzelfällen eine adäquate Lösung für solche Patienten darstellen, die vor einem Elektiveingriff stehen, bei dem mit mindestens $10 \%$ iger Wahrscheinlichkeit eine Bluttransfusion notwendig werden wird und bei denen eine Vorsensibilisierung gegen erythrozytäre Antigene besteht oder aber aufgrund z.B. eines differenten ethnischen Hintergrunds eine solche Sensibilisierung befürchtet werden muss. Viele Patienten kommen aufgrund ihrer Vorerkrankungen, Begleitmedikation oder präoperativ durchgeführten Voruntersuchungen für eine PABD nicht in Frage. Für die autologe Hämotherapie muss unserer Meinung nach eine sehr strenge Indikationsstellung erfolgen, da hohe Kosten, hohe Verwurfraten, die Risiken für den Eigenblutspender durch den Spendevorgang und eine komplexe Logistik für Patient und Krankenhäuser im Normalfall nur sehr geringen Vorteilen gegenüberstehen. Im Übrigen kann PABD nur wenig zur Sicherung einer ausreichenden Blutversorgung beitragen. PABD in fehlerfreier Anwendung, die in der Realität nicht vorkommt, würde die Infektionsrisiken durch bekannte und unbekannte Pathogene mit Ausnahme der Bakterien zwar reduzieren. In «Real life»-Situationen scheint aber das Risiko für Verwechslungen, ABO-inkompatible Transfusionen und die Übertragung der transfusionsrelevanten Viren HBV, HCV und HIV bei PABD nicht geringer zu sein als bei Fremdblut. PABD reduziert das Risiko der Alloimmunisierung gegen erythrozytäre Antikörper und hat hier seine Bedeutung. Auf der anderen Seite erhöht die PABD das Risiko für den Spender bei der Spende und danach. Eigenblut scheint aufgrund der Spendercharakteristik und der verlängerten Lagerungsdauer eine geringere Qualität sowie ein höheres bakterielles Kontaminationsrisiko verglichen mit Fremdblutprodukten zu besitzen. Der Eigenblutspender hat insgesamt ein signifikant erhöhtes Risiko, perioperativ eine Transfusion zu erhalten. Dies ist durch die signifikant geringeren Hämoglobinwerte beim Eigenblutspender präoperativ (so genannte iatrogene Anämie) sowie eventuell durch die fehlerhaft liberalere Transfusionsstrategie beim Eigenblut bedingt. Eine nicht unerhebliche Anzahl von Patienten, die im Rahmen ihres Elektiveingriffs keine Bluttransfusionen benötigen würden, tritt durch die PABD letztlich in die Transfusionskette ein mit allen damit verbundenen Risken sowohl als Eigenblutspender als auch als Transfusionsempfänger.

\begin{tabular}{|c|c|}
\hline KARGER & (C) 2006 S. Karger GmbH, Freiburg \\
\hline $\begin{array}{l}\text { Fax +4976145207 } 14 \\
\text { E-mail Information@Karger.de } \\
\text { www.karger.com }\end{array}$ & $\begin{array}{l}\text { Accessible online at: } \\
\text { www.karger.com/tmh }\end{array}$ \\
\hline
\end{tabular}




\section{Introduction}

In December 1991, the German Federal Supreme Court (Bundesgerichtshof) decided that patients must be informed about hepatitis and HIV infection risks due to homologous blood, when intra- or postoperative transfusion in planned surgical procedures becomes likely with a probability of at least $10 \%$. In such cases, patients have to be informed by the treating physician about autologous blood donation as an alternative to homologous blood, as far as this option is feasible in the individual case. This decision was well founded in the 1990s due to the experience of a considerable risk of transmission of viral hepatitis and HIV by transfusion in the 1980s. Since that time, however, thorough selection of blood donors by history, questionnaire, examination and exclusion of donors at risk for transmissible diseases as well as improved laboratory testing including mandatory nucleic acid testing (NAT) for HCV and HIV have diminished these risks of viral transmission for recipients of blood products to a very low residual risk. Therefore, the usefulness of preoperative autologous blood donation (PABD) has to be re-assessed, and the risk-benefit analysis of this procedure should be repeated. In addition, a costbenefit analysis is worthwhile to be done in times of financial shortages in the health care systems.

This article will only deal with PABD and will not assess risks and benefits of other categories of autologous hemotherapy such as acute normovolemic hemodilution or perioperative (blood) cell salvage.

\section{Presumed Benefits of PABD}

PABD is often still appreciated for several potential benefits:

- reduction of allogeneic (= homologous) blood consumption, with homologous blood products being in short supply,

- no transmission of transfusion-associated viruses

- no risk of transmission of other pathogens and, therefore, higher quality of autologous compared to homologous blood products,

- no clerical error since the donor gets back his own blood product only,

- no risk of adverse events for the patient,

- no induction of alloantibodies,

- no additional logistic expenditure and low costs,

- active involvement of the patient.

In the following sections, we would like to discuss the abovementioned presumed benefits step by step.

\section{Assumption 1: PABD Contributes Significantly to the Overall Blood Supply in Germany}

In Germany, a lack of blood products for some specific blood groups occurs regularly in early summer due to the begin-

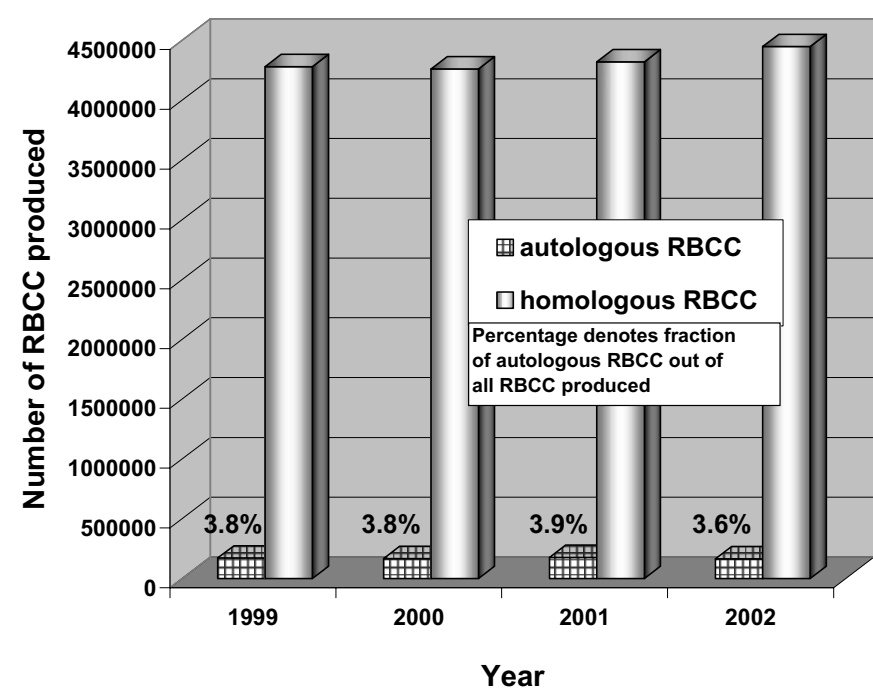

Fig. 1. Proportion of PABD products (RBCC) and homologous $R B C C$ of all RBCC produced in Germany from 1999 to 2002 [adapted from 1, 2].

ning of the holiday season. Genuine alternative options might be able to find a way to compensate for the scarce resources. In acute medical conditions such as accidents, acute illnesses, nonelective, acute surgical procedures and hematological or oncological diseases requiring blood products, PABD is not feasible. The same holds true for anemic patients, e.g. in intensive care, hematology/oncology or nephrology units. The average patient willing to donate autologous blood preoperatively is further burdened by sometimes multiple diseases and significantly older compared to the average healthy volunteer homologous blood donor. Therefore, a considerable number of these patients has to be excluded from PABD for medical reasons. Due to storage as well as technical/logistic reasons, the number of red blood cell concentrates (RBCC) obtained by PABD (on average 2-3) is not sufficient in case of a (severe) bleeding complication in the succeeding surgical procedure.

In conclusion, autologous blood products constitute only a miniscule fraction of the annually required blood products in Germany as depicted in figure 1. In 2002, this fraction of autologous RBCC comprised only about $3.6 \%$ of the total number of RBCC produced [2]. It is well-known and has recently been published [2] that about one third of the autologous RBCC produced are not used and discarded. At the same time, it has to be assumed that about $30 \%$ of the finally transfused autologous RBCC are not medically indicated, for example because the transfusion triggers are not met. Erroneously, a more liberal transfusion strategy was adopted for autologous compared to homologous (= allogeneic) blood products at some places. Therefore, autologous blood products in Germany can only cover about $2 \%$ of the blood products needed and only in a specific subpopulation of patients requiring blood transfusions [3]. 


\section{Assumption 2: PABD Prevents Transmission of Viruses via Blood Products}

Autologous blood products in ideal situations where no human clerical errors occur and a mix-up of diagnostic blood samples as well as blood products is completely avoided theoretically reduce the risk for transfusion-associated transmission of viral and unknown pathogens. This was the main reason for introduction and promotion of PABD in the 1980s and 1990s.

However, an ideal situation is desirable, but real life situations on the wards, in outpatient departments, in operating rooms or in emergency rooms tell us that clerical errors do occur. Autologous blood products and the PABD procedure itself are subject to similar conditions as the homologous blood transfusion procedure: As analyzed in retrospective analyses [4-7], ABO-incompatible autologous transfusions due to clerical errors, occur in 1:5,000 to 1:31,000 transfusions. This rate of human errors is comparable to the mix-up rate found retrospectively in transfusion of homologous blood products (reviews in [8-10]). Transfusion to the wrong patient is therefore deemed likely to be the most important transfusion risk nowadays [9]. Hence, Linden [7] concluded that 'autologous blood is not immune from error and poses infectious disease risks as well as the risk of hemolytic transfusion reaction ...'. Therefore, the prevalence of virus infection markers in autologous blood donor populations becomes an important factor in assessing infectious risks of PABD.

We compared infectious risk markers for HBV, HIV and $\mathrm{HCV}$ in autologous and homologous blood donations made between 1996 and 2002 in our institute in Frankfurt/M. Testing for viral infections was performed using serological as well as PCR techniques. Out of 19,851 autologous samples tested, $0.232,0.343$ and $0.005 \%$ were tested positive for $\mathrm{HBV}, \mathrm{HCV}$ and HIV, respectively. In comparison, out of 1,307,170 homologous samples tested at the same time, 0.02, 0.02 and $0.001 \%$ were tested positive for HBV, HCV and HIV, respectively [11]. Thus, viral infection markers in our autologous donor population were 10 times higher for $\mathrm{HBV}$ and $\mathrm{HCV}$ and 5 times higher for HIV compared to our homologous donors. These findings might be explained by the facts that i) a major proportion of autologous blood donors are first time donors compared to $>90 \%$ multiple donors in our homologous blood donor population, ii) autologous donors are older patients with a higher lifetime cumulative infection risk, and iii) autologous donor selection criteria are less restrictive compared to the criteria for homologous donors.

The current German guidelines for production of blood and blood components and for application of blood products (hemotherapy) laid down by the German Federal Medical Association (Bundesärztekammer) and the Paul Ehrlich Institute (PEI) in 2005 [12] state, that, in contrast to homologous blood products where NAT for HCV and HIV has to be negative before product release, in PABD only serological testing for
HCV, HIV and HBV must be performed before or at the first PABD. Autologous blood products tested positive for these markers must undergo an additional risk-benefit analysis by which PABD and re-transfusion of such a product has to be re-evaluated by the treating physician, but is still possible.

On the other hand, during the last decades, viral infection risks in homologous blood products - the reason for establishing PABD once - became more and more 'theoretical' residual risks. Rigorous exclusion of homologous blood donor populations with a higher infectious risk profile and of individual donors with acute or chronic risks becoming apparent after an elaborate history by questionnaire and medical examination, the preference of unpaid versus paid volunteer donors whenever possible, and the introduction of novel test systems like NAT for HCV, HIV, HBV, HAV and parvovirus B19 led to residual virus transmission risks, which are currently lower than the risk for being killed by lightning. The observed frequency of transfusion-associated HIV or HCV transmission from a blood product of the German Red Cross blood donor services was lower than 1 in 20 million products released, and the frequency for hepatitis B transmission was close to 1 in 500,000 blood products (observation period 1997-2005). The higher risk for hepatitis B is now further reduced by establishing anti-HBc testing in all healthy volunteer blood donors. Calculated risks for transmission of transfusion-associated viruses are somewhat higher due to the statistical methods used. This is not a topic of this paper. In conclusion, the main reason for the establishment and promotion of PABD in Germany, the experience of a considerable risk of transmission of viral hepatitis and HIV by transfusion of homologous blood products in the 1980s, is almost vanished or significantly reduced nowadays by the measures discussed above to a more or less theoretical residual risk.

Bearing in mind the similar clerical error rate for autologous and homologous blood products mentioned above, it is therefore crucial to destroy autologous donations with positive infection markers to avoid a higher risk of transmission of viruses for patients involved into the PABD process. If such PABD products with positive infection markers are not discarded as soon as the positive result is known, this might endanger the homologous transfusion chain as well. Clerical errors and mixup of products as described above might happen not only within one transfusion chain (autologous or homologous): PABD products with positive infection markers might also appear in the homologous transfusion chain by a clerical error (about 1 in 30,000 blood products transfused), and in such cases, the risk for transmission of an infected blood product suddenly rises from 1 in several millions of RBCC transfused to a significantly higher risk. In very particular cases, which are extremely rare events, where complex immunohematologic problems make PABD mandatory, such donations with positive viral markers must be stored separately from other blood products with an unambiguous labeling showing the positive result for the infection marker tested. In such cases, 
advise from a specialized center should be sought for product logistics.

The PABD process must be accompanied by a well established quality control system and should be managed by a comprehensive computer system, including electronically printed and bar code labels for the autologous products to avoid clerical errors as far as possible and to establish a manufacturing quality similar to that established for homologous blood products.

\section{Assumption 3: PABD Bears No Risk of Transmission of Other than Viral Pathogens and Comprises a Higher Quality Compared to Homologous Blood Products}

In European countries nowadays, bacterial contamination of blood products, especially, but not exclusively, of platelet concentrates (PC), is the most common transfusion-related microbiological risk, exceeding viral transmission risks by far [review in 13]. Transfusion-transmitted bacterial infection might occur in RBCC too, but due to storage conditions at $4{ }^{\circ} \mathrm{C}$ (compared to $22^{\circ} \mathrm{C}$ for PC), only few bacterial species will be able to grow and pose a threat for septic reactions to the recipient. While in PC contamination rates of 1 in 2,000 to 1 in $3,000 \mathrm{PC}$ and fatal septic complications of about 1 in 100,000 to 1 in $250,000 \mathrm{PC}$ were estimated, the risk for bacterial contamination of RBCC seems to be significantly lower. Contamination of RBCC with e.g. Yersinia spp. were reported in up to 1 in 40,000 RBCC [review in 13]. Bacterial contamination of RBCC leading to significant clinical complications of the recipient up to death has never been examined accurately. However, estimates from different sources $[13,14]$ for severe septic episodes due to contaminated RBCC leading to major morbidity and mortality in the recipients vary from 1 in 500,000 to 1 in 4,700,000 RBCC.

Since PABD comprises almost exclusively RBCC, bacterial contamination is a rare, albeit potentially dramatic and clinically significant risk. A bacterial contamination study at the PEI compared this risk in autologous versus homologous RBCC: Out of 23,716 autologous donations, 5,274 (22.2\%) were tested while $28,184(0.7 \%)$ out of $4,059,302$ homologous donations were checked. The results showed a higher bacterial contamination rate for autologous blood products $(0.25 \%$ for autologous RBCC versus $0.1 \%$ for homologous RBCC). In our own small quality control comparison of autologous versus homologous blood products, bacterial contaminations were detected in $0.32 \%$ of the autologous samples and in $0.06 \%$ of the homologous samples (313 autologous samples versus 4,966 homologous samples tested 1997-2003). Though small and therefore not statistically analyzable, these data show that the bacterial contamination risk for PABD might be somewhat higher than that for homologous blood products. What are the potential reasons for this observation?

Autologous blood donors as a group are significantly older than healthy volunteer homologous blood donors. With increasing age, the numbers of donors tested positive for all infectious disease markers increase likewise (= cumulative lifetime risk; Sireis, unpublished data). As mentioned above, most of our homologous blood donors (>90\%) are multiple donors donating regularly, therefore repeatedly answering questionnaires, undergoing recurrent medical history taking, examinations and testing, and being well aware of potential health problems. In contrast, autologous donors are quite often either first time donors or have donated their last homologous blood product quite a long time ago. Most PABD donors would never be eligible for homologous blood donation because they do not meet the criteria for healthy volunteer blood donors. Autologous donors are patients with often complex disease histories, multiple concomitant diseases and consequential drug intake, sometimes either compromising immune competence (e.g. diabetes) or (more often) physiological skin and mucosal barriers (e.g. circulatory disorders). In addition, preoperatively performed diagnostic procedures such as arthroscopies, gastroscopies or colonoscopies are potential reasons for bacteremia as well. In some patients, a higher level of cytokines and inflammation mediators which is often being triggered by or combined with chronic inflammation is present in the blood due to their underlying disorders. Underreporting bias, e.g. the denial of own concomitant diseases and/or risk factors, sometimes occur for the (irrational) fear of homologous blood products. The patient fears to become deferred from PABD temporarily (which might delay the surgical procedure planned) or permanently and therefore deliberately or unconsciously skips critical parts of the personal history. Another minor reason for higher contamination rates might be the longer storage period of RBCC due to the PABD procedure. PABD is only reasonable if the time period between the last donation and the planned surgical procedure is long enough for the patients' bone marrow to restore as much erythrocytes as possible. Maximized intervals on the other hand at least theoretically should give slow-growing (psychrophilic) bacteria a chance to contaminate the blood product. However, quality control data of (homologous) RBCC at the end of the storage time (35-42 days) did not show higher rates of bacterial contamination compared to RBCC tested earlier during their shelf life.

Apart from the reasons discussed above, older blood products have a lower quality due to reduced erythrocyte metabolism and a higher rate of cell destruction and hemolysis. One example is the well-known ongoing reduction in 2,3-diphosphoglycerate (2,3-DPG) levels in red cells with increasing storage time. In cases of emergency, when the patient instantly requires fully functional red blood cells, there is no time to replenish low 2,3-DPG levels in the circulation first.

Thus, in general autologous blood products are of lower quality compared to homologous blood products.

The group of emerging pathogens (table 1) threatened global blood safety in the past and will probably not stop doing so in 
Table 1. Examples for novel or re-emerging pathogens with the potential of becoming a global threat since the 1960s [modified from 15, 16]

\begin{tabular}{|c|c|}
\hline Year & Pathogen \\
\hline $1960 \mathrm{~s}$ & Marburg virus and other viral hemorrhagic fevers (VHF) \\
\hline 1973 & Rota virus \\
\hline 1976 & Cryptosporidium spp. \\
\hline 1976 & Ebola virus (VHF) \\
\hline 1977 & Legionella spp. \\
\hline 1977 & Hantaan virus \\
\hline 1977 & Campylobacter jejuni \\
\hline 1979 & Babesia spp. \\
\hline 1980 & HTLV-1 \\
\hline 1981 & Borrelia burgdorferi / Lyme disease \\
\hline $1981 / 1982$ & HTLV III (= HIV-1) / AIDS \\
\hline 1982 & Escherichia coli $\mathrm{O} 157: \mathrm{H} 7$ \\
\hline 1982 & HTLV-2 \\
\hline 1983 & Helicobacter pylori \\
\hline 1986 & Cyclospora spp. \\
\hline 1986 & HIV-2 \\
\hline 1986 & Ehrlichia spp. \\
\hline 1988 & human Herpes virus 6 (HHV 6) \\
\hline 1988 & hepatitis E (Caliciviridae) \\
\hline 1989 & hepatitis C (Flaviviridae) \\
\hline 1992 & Vibrio O 139 \\
\hline 1992 & Bartonella hensellae \\
\hline 1993 & Sin Nombre virus \\
\hline 1995 & hepatitis G (Flaviviridae) \\
\hline 1995 & $\mathrm{HHV}^{*} 8$ \\
\hline 1996 & variant Creutzfeldt-Jakob disease (vCJD); prions \\
\hline 1997 & avian influenza virus Type A (H5N1)) \\
\hline 1999 & West-Nile virus (Flaviviridae) in U.S.A. \\
\hline 1999 & Nipah virus \\
\hline 2003 & SARS (Coronaviridae) \\
\hline 2003 & monkeypox virus \\
\hline 2003 & metapneumovirus \\
\hline
\end{tabular}

the future. Hemovigilance and infection epidemiology as well as quality control of blood products will always have to pay attention to these emerging pathogens as they come up or threaten to spread from an endemic to a global disease [15, 16]. However, most of these diseases are threats for both autologous and homologous blood supply as the donor itself will fall ill and, therefore, probably become unavailable for donation. Only a few diseases with long, clinically unapparent incubation periods are specifically problematic for the safety of the blood supply. In the following, we will discuss a very important recent example, the prion protein disease variant Creutzfeldt-Jakob disease (vCJD).

Since a possible transmission of prion disease via transfusion of blood products was reported not only in animal studies [17] but also in three human cases up to now in the UK [18-20], the question of an increased risk for transmission of the misfolded pathological prion protein $\mathrm{PrPSc}^{\mathrm{Sc}}$ to recipients of blood products from a clinically unapparent donor became pressing. In the UK, 159 probable or definite vCJD cases were registered up to February 2006, 154 of these already died. In France, 15 vCJD cases occurred up to autumn 2005 as well as few cases elsewhere (Ireland 3; Italy, The Netherlands, Portugal, Spain, Saudi Arabia, Canada, USA, Japan, Hong Kong 1 each), most of the latter cases probably acquired in the UK where most of these patients lived for some time. The physiological prion protein $\mathrm{PrP}^{\mathrm{C}}$ is encoded by a single gene called PRNP. Single nucleotide polymorphisms (SNPs) of this gene have been described. A SNP at codon 129 of PRNP coding for methionine $(\mathrm{M})$ or valine $(\mathrm{V})$ is responsible for a significant difference in the susceptibility to and the incubation period of human prion diseases [review in 21]. To date, all clinical vCJD cases in the UK are homozygous for methionine at codon $129(\mathrm{M} / \mathrm{M})$. Whether heterozygous (M/V) or homozygous individuals for valine (V/V) at codon 129 are more resistant to $\mathrm{PrPSc}^{\mathrm{Sc}}$ or to the development of clinical vCJD remains to be elucidated. However, the second case of a potentially transfusion-transmitted prion disease in the UK was preclinical vCJD in a PRNP codon 129 heterozygous (M/V) patient who did not show any clinical signs of vCJD nor $\mathrm{PrP}^{\mathrm{Sc}}$ in the central nervous system when he died from another non-neurological disease.

In Germany, no cases of vCJD have been reported up to now. However, on principle, people in Germany might come down with vCJD due to nutritional risks as well as in other EU countries. Until the beginning of the 21st century, carcass meal was fed to cattle and other animals in Germany as well. Therefore, in Germany, an infectious risk via infected animals existed too. The food chain is a potential and well-known infection pathway for $\mathrm{PrPSc}^{\mathrm{Sc}}$.

But can we roughly estimate the current risk for the German population?

To approach such a question, it seems necessary to compare the cattle disease BSE in EU countries. The number of detected cases of BSE (bovine spongiform encephalopathy; mad cow disease) either by veterinarian or test result are shown in figure 2 for the UK, France and Germany from 1988 to 2005. BSE peaked in the UK in 1992, which is 9 years earlier than in France and Germany, where the peak was in 2001. The peak numbers for BSE in the UK are not comparable to the central European cases and are about 300-fold higher compared to the German observations. As for the cumulative BSE cases, the UK numbers are almost 500-fold higher than the German data (395 BSE cases until the end of 2005) where more than 13 million animals were tested since 2001 .

A matter of particular interest is the comparison of the above mentioned UK BSE course and the development of human vCJD cases in the UK as depicted in figure 3. The vCJD peak in the UK in 2000 is 8 years later than the UK BSE peak. One has to be extremely cautious to transfer such data from different species and to convey the results to other countries with different conditions. However, such procedures might give some deeper insight into a currently non-existing clinical problem in Germany. If we assume a decline in newly diagnosed BSE as well as vCJD in the UK (fig. 3), a sensible assumption as long as PRNP codon 129 heterozygous (M/V) 


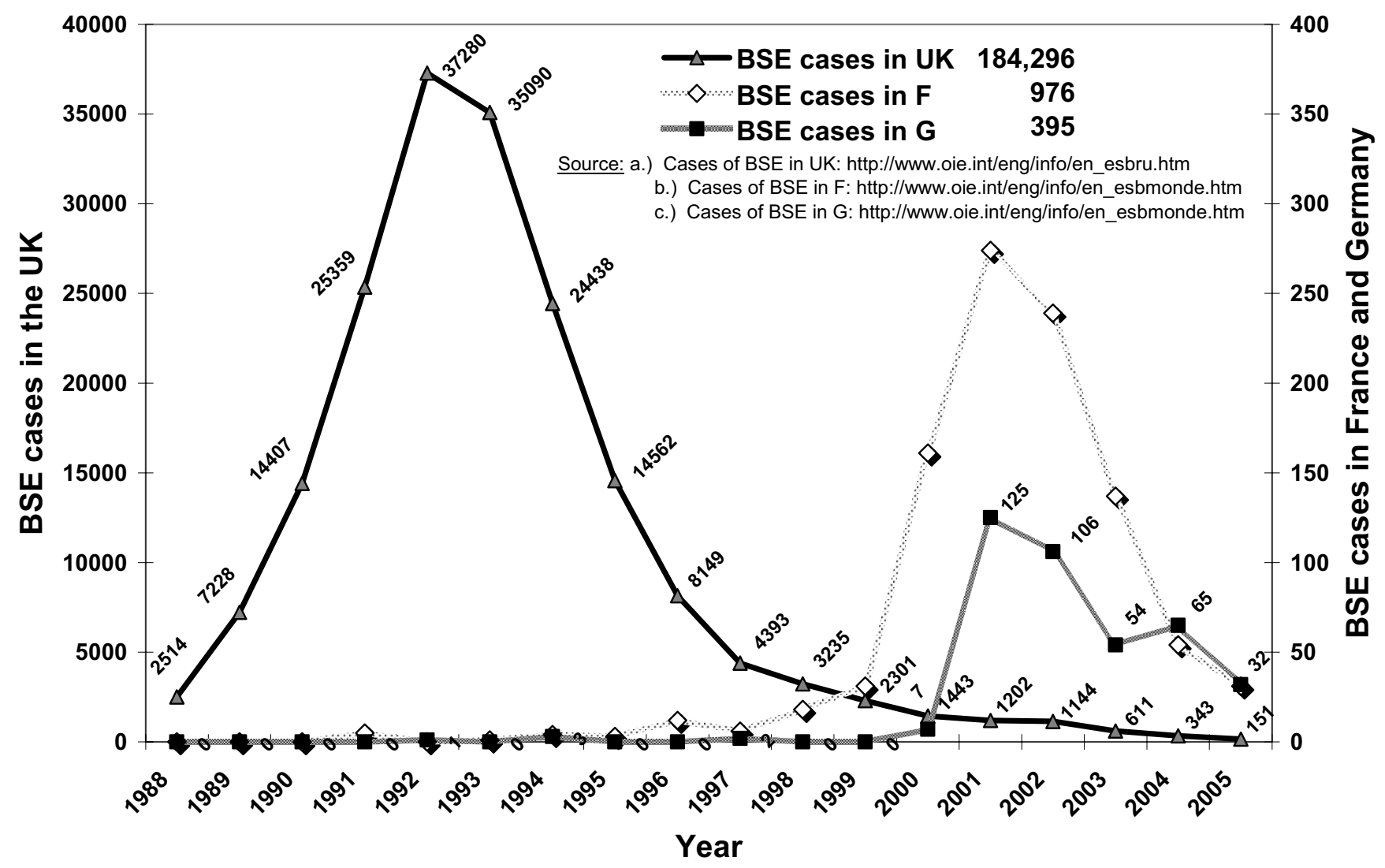

Fig. 2. Comparison of BSE cases in the UK, France and Germany from 1988 to 2005. Please note the different scales of both ordinates! Data sources are depicted in the figure.

and valine homozygous ( $\mathrm{V} / \mathrm{V})$ individuals will not succumb to the neurological disease after a longer incubation period currently not reached, a risk estimate might be possible for such a (currently not existing) situation in Germany. Using the UK data (159 human vCJD cases versus 184,296 BSE cases $\cong 1$ in about 1,150) for our assumption, the calculation for the German cumulative BSE cases would be as follows: 395/1,150 = 0.34 vCJD patients could cumulatively be expected in Germany. This is probably a very rough estimate and might underestimate the real situation.

The Scientific Committee on Emerging and Newly Identified Health Risks (SCENIHR) of the European Commission published an estimate of the safety of human-derived products with regard to vCJD only recently [22]. On the basis of mathematical models, this group discussed a risk calculation regarding potentially infected blood donations and the risk for the recipients in the UK. A 'worst case' scenario assumed 1,250 infected donations a year for the UK, leading to 1,875 newly infected individuals who will eventually develop vCJD. The basis for this computation however was considered unrealistic by these authors. A much more realistic calculation from practical as well as scientific points of view is also published in this opinion: According to this more realistic calculation, 9 infected donations per year might occur in the UK. The authors also stated that their calculations were based on the UK appendix study in which appendices of UK surgical patients were anonymously screened for $\mathrm{PrP}^{\mathrm{Sc}}$. Such data are lacking for other EU countries. Therefore, similar calculations as that for the UK cannot be performed. The authors nevertheless state, that '... based on the current observed number of cases of vCJD within the Member States [of the EU], an estimate for the risk for France ... would be $10 \%$ of that calculated for the UK while for other Member States it will be considerably lower.' [22; p. 44]. If we apply our calculation as above where Germany has less than $1 / 1,000$ of the UK risk burden, the unrealistic 'worst case' assumption would lead to 1 infected donation per year in Germany while, using the much more realistic assumption, 0.009 donations/year would be potentially infectious. If one calculates the cumulative risk for Germany for the next 30 years $(30 \times 0.009)$, the result of 0.27 infected blood products is close to the calculation above.

Another model (Dietz, personal communication) assumes a cumulative vCJD disease rate in Germany of 400 patients over the next 30 years. A rate of $3 \%$ of blood donors in the German population and a mean cumulative frequency of about 5 donations per donor leads to the assumption of 60 infected donations. Using an assumed infectivity of $30 \%$ and a rate of 1.4 blood products made out of one whole blood donation on average, 25.2 recipients might be infected. Since less than $50 \%$ of recipients of blood products live long enough ( $>5$ years) to suffer from vCJD or donate blood by themselves, 12.6 recipients at most might fall ill over the next 30 years due to transmission 


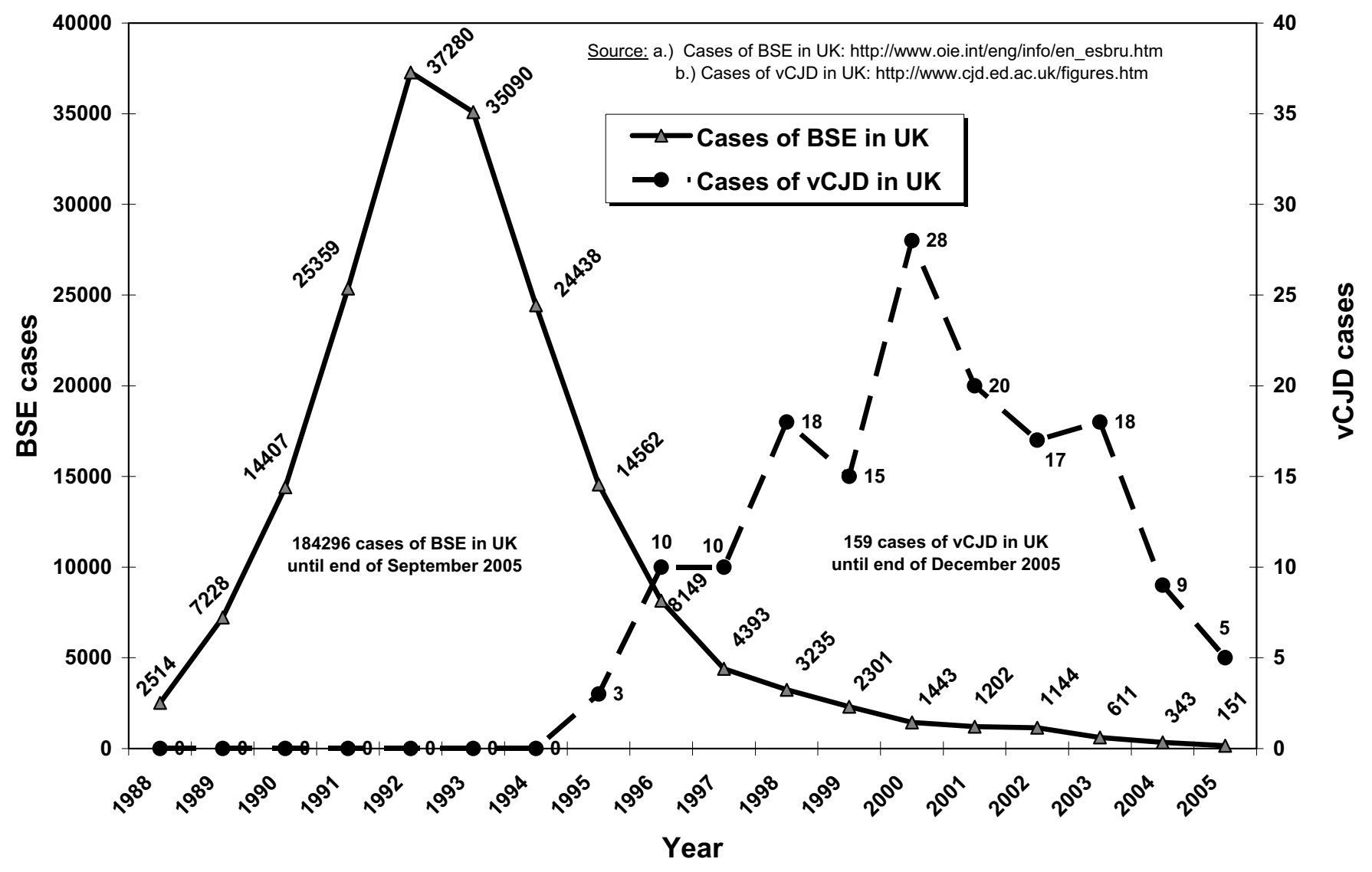

Fig. 3. Comparison of BSE cases in the UK and human cases of vCJD in this country from 1988 to 2005. Please note the different scales of both ordinates! Data sources are depicted in the figure.

by blood transfusion, leading to an incidence of 0.42 per year. A mathematical modeling for the risk whether the vCJD infection could establish itself in the population was reported by the SCENIHR experts as well (Dietz). This model predicts that an infection could not become endemic by transfusion alone and that only few cases could be avoided by excluding donors with a transfusion history. The SCENIHR committee [22] in its conclusion did not consider that specific measures might be needed at this time to reduce the risk from vCJD infectivity in blood products.

All these assumptions suffer from the fact that, apart from the UK appendix and tonsils studies, no reliable data for the prevalence of $\mathrm{PrP}^{\mathrm{Sc}}$ in the EU population are available. Furthermore, the fate and infectivity of infected individuals who are codon 129 homozygous for valine (V/V) or heterozygous $(\mathrm{M} / \mathrm{V})$ is currently unknown. Therefore, although there is no case of vCJD in Germany until now and the assumption that vCJD might be transmitted by blood transfusion in Germany is speculative, one should keep the discussed cave in mind. The lifelong exclusion of blood donors who stayed in the UK for more than 6 months between 1980 and 1996 and of all donors who underwent surgical procedures in the UK are additional safety measures to reduce risks.

For our discussion of pathogen transmission and PABD, the vCJD risk currently does not play a major role compared to the relevant infectious and noninfectious risks like for example bacterial contamination or clerical errors.

In conclusion, bacterial infection risks are a major threat for the recipients' safety, and these risks tend to be even higher for PABD compared to homologous blood products. PABD products are older RBCC compared to homologous RBCC, donated by a patient with concomitant diseases, procedures performed and drug intake. Therefore, their quality in general is lower compared to homologous blood products. The clinical relevance of the so called 'non-transfusion-relevant and new viruses' is unknown in this regard. Up to now, vCJD in Germany is not a clinical but a theoretical issue for the transfusion chain.

\section{Assumption 4: No Clerical Errors Since the Donor Gets Back His Own Product Only}

This assumption was already disproved above (see above 'Assumption 2: PABD Prevents Transmission of Viruses via Blood Products'): In real life situations, the risk for clerical errors and, therefore, a mix-up of products is at least as common in PABD procedures as in homologous blood products. However, in a given clinic or outpatient ward with less PABD procedures performed, the less experienced staff has to deal with often insufficient technical support. In small units, in-process 
control of production via computer systems and printed and bar code labeled blood bags are often not available: Handwritten labels pose high risks of writing/reading errors, for example.

In conclusion, a production not compliant to good manufacturing practice (GMP) or the absence of standard operating procedures (SOPs) and non-accredited operations in some of the smaller facilities offering PABD cannot guarantee for the required uniformly high quality of the products or the procedures. Therefore, the occurrence of clerical errors is at least as common and might even be higher for PABD compared to homologous blood products with all the risks discussed above. Because cross-matching is not mandatory for PABD products, the risk of an ABO-incompatible transfusion is even enhanced for autologous blood products.

\section{Assumption 5: No (Increased) Risk for the Patient}

Since patients eligible for PABD are generally older than the average homologous donor and often burdened with multiple concomitant diseases, not always known to the patient as well as to the treating physician, the donation procedure itself and the drop in oxygen carriers pose a certain risk to these donors. Popovsky et al. [23] published an analysis of severe outcomes of allogeneic (= homologous) and autologous blood donations in the USA in 1995. They defined a very severe outcome (VSO) as an event requiring hospitalization. These VSOs were nearly 12 times as likely in autologous donors as in homologous donors. Mean hospital stay in this analysis was 1.9 days for a VSO. The authors concluded that, even though infrequent, the occurrence of a VSO may be associated with significant morbidity and costs.

Davenport [24] analyzed PABD hazards not directly associated with blood transfusion itself. Travel risks to and from the PABD center, mainly by car, are not negligible in view of the small remaining risks of transfusion of a homologous blood product: The risk for traffic-related death and traffic-related injury to and from the autologous donation appointments approximate in his analysis the estimates of the risks for infectious disease transmission or serious transfusion reactions. Therefore, the author concludes that 'autologous blood donors may unwittingly incur hazards that are as likely and as serious as those associated with allogeneic blood transfusion'. Another important problem for the patient is iatrogenic anemia caused by PABD. A Cochrane review published recently [25] examined the efficacy of PABD in reducing the need of perioperative blood transfusion. Randomized controlled trials in adults scheduled for nonurgent surgery were analyzed. As a result of this analysis, PABD reduced the risk of receiving an allogeneic RBCC by $63 \%$ (relative risk (RR) 0.37 ; $95 \%$ confidence interval (95\% CI) 0.26-0.54; absolute risk reduction $43.8 \%$ ). On the other hand, PABD increased the risk of receiving any blood transfusion, either allogeneic or autologous, by $30 \%$ (RR 1.29; 95\% CI 1.12-1.48). A potential reason for this is the induction of anemia, i.e. iatrogenic anemia, by the PABD preoperatively, which brings these patients closer to a (predefined) transfusion trigger. The perioperative blood loss consequently adds to this. At some places, a more liberal transfusion strategy for autologous blood products is used. All these factors leading to the more frequent indication for transfusion in PABD patients with the already described risks of bacterial contamination, clerical errors, etc., irrespective of the source of the RBCC transfused (autologous/homologous).

The International Study of Perioperative Transfusion (ISPOT) [26] came to similar results and conclusions.

In the preparation and planning of nonurgent operations, the treating physician must take into consideration that the prevalence of anemia in older patients is not negligible. A recent population survey [27] in US residents 65 years and older revealed a rate of anemic persons greater than $20 \%$ at an age of 85 years and older. Overall, $11 \%$ of men and $10.2 \%$ of women 65 years and older were anemic. Albeit some of the causes of anemia in older people might not be easy to diagnose and to treat (the so called unexplained anemias), nutritional and resorption problems causing iron, folate and vitamin B12 deficiencies, anemia of chronic inflammation, and absolute or relative erythropoietin deficiency (e.g. in renal insufficiency) are manageable problems before planned surgery.

But then, an increasing number of nonurgent operations get by without any transfusion at all. Adherence to specified (lower) transfusion triggers for homologous as well as autologous blood transfusion and the use of hemostatic measures and antifibrinolytic agents like aprotinin have reduced the number of interventions requiring blood products. Novel, less traumatic surgical procedures and intraoperative blood cell salvage have been widely established. Hip replacement surgery and total knee arthroplasties, orthopedic procedures well known for being indications for PABD in the past, can be managed without PABD [28, 29]. Bilote et al. [28] stated in their conclusions that 'preoperative autologous donation provides no benefit for nonanemic patients undergoing primary total hip replacement surgery. Preoperative autologous donation increased the likelihood of autologous transfusion, wastage of predonated units and costs.' The aspects of increased wastage and costs will be discussed below. However, it is important to realize that in the hip replacement study of Bilote et al. [28], out of 96 patients completing the study (42 with and 54 without PABD), no patient in either group required allogeneic blood transfusion, but 29/42 patients in the PABD group (69\%) received an autologous transfusion. Even though the hemoglobin values at admission to the hospital (after PABD) and in the recovery room were significantly lower in the PABD group compared to those of the nondonors, hemoglobin values in the PABD group in the recovery room $(104 \pm 12 \mathrm{~g} / \mathrm{l})$ were clearly above today's widely accepted transfusion trigger for RBCC. On the other hand, even taking into account the obviously more liberal transfusion strategy 
Fig. 4. Reported transfusion-related events numbers of HLA antibody-positive recipients out of these reported incidents: Please note was introduced in Germany in 2001. and incidents 2000-2003 in our institute and that inline filtration (universal leukoreduction)

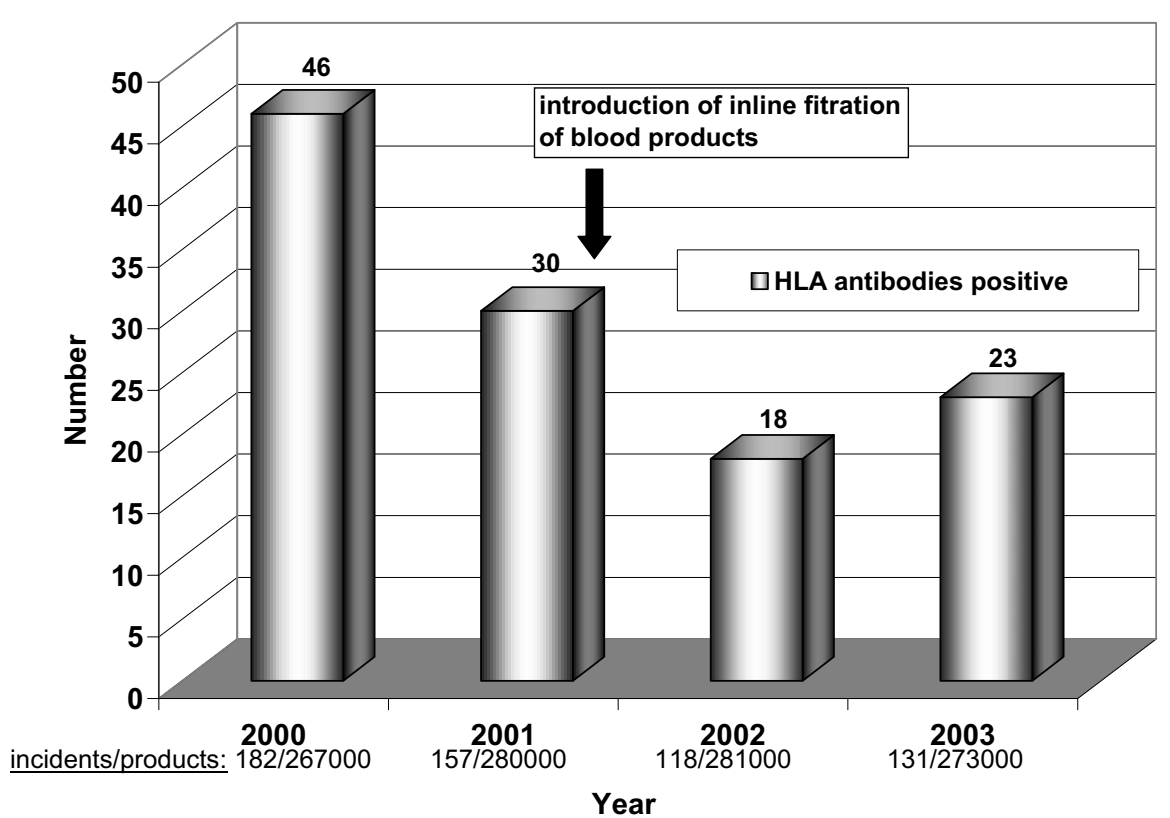

for autologous blood products (which is not justified recalling the above discussed risks), $41 \%$ of the autologous units were wasted. This meant additional costs of USD 758.- per patient in the PABD group in this study.

Kanter et al. [30] performed a retrospective PABD analysis in 263 elective hysterectomy patients. Out of the 263 patients analyzed, 26 (10\%) received a blood transfusion. The major risk factor for transfusion in this study was PABD: Out of the 140 PABD patients, 25 received a transfusion, whereas only 1 out of 123 patients who had not donated autologous blood was transfused $(\mathrm{p}<0.001)$. The authors concluded that for their patient group donation of autologous blood caused (moderate) anemia and was associated with a more liberal transfusion strategy. The authors stated that 'these 2 factors result in a markedly increased incidence of transfusion with its associated risks'.

Similar results were found in patients undergoing radical prostatectomy, a procedure historically known to have high transfusion rates [31].

In conclusion, in counseling, the risk-benefit ratio of PABD has to be assessed for each individual patient, and the patient must be informed about her or his individual constellation: The higher risk for donation-associated complications in the older PABD population and the induction of iatrogenic anemia have to be considered, bearing in mind that for an increasing number of standard surgical procedures, no blood transfusion, neither autologous nor homologous, is required. In cases of a severe perioperative bleeding or bleeding complication, the two PABD RBCC normally donated preoperatively are very often insufficient and need to be supplemented by homologous blood components all the same. A French study by MathouilinPelissier et al. [32] was able to detect that, out of 376 patients undergoing different surgical procedures and having received autologous blood transfusion, almost one fifth were exposed to additional allogeneic transfusion.
It is therefore much more important in most cases to diagnose and correct preexisting anemia than to perform the PABD procedure, which might jeopardize the patient, and in the end to probably discard the stored autologous blood. If a more liberal transfusion strategy for PABD versus homologous blood products is adopted, this would stand for treatment without indication, introduce the risk of 'over-transfusion' and expose the patient to the above mentioned, however, small risks of any transfusion without a potential benefit.

\section{Assumption 6: No Induction of Alloantibodies}

The induction of antibodies against allogeneic antigens on the surface of red blood cells (erythrocyte antigens) and - to a smaller extent - the induction of antibodies against human leukocyte antigens (HLA) are well-known problems of homologous blood transfusion. Having said that, it has to be mentioned that the introduction of universal leukoreduction by inline filtration of blood products in Germany in 2001 led to a marked reduction of the incidence of HLA antibodies as depicted in figure 4.

Likewise, the occurrence of antibodies against erythrocyte surface antigens is clinically relevant in some subpopulations only. Firstly, a positive direct antiglobulin test alone is not sufficient for the definition of a hemolytic transfusion reaction, the clinically relevant event following alloimmunization against erythrocyte surface antigens. Therefore, the reported incidences of alloimmunization have to be carefully assessed regarding clinically relevant antibodies. Antibodies that appear to react at $37^{\circ} \mathrm{C}$ and therefore being of potential clinical significance have been reported to occur in 1 up to $3.5 \%$ of hospital patients [review in 33]. Schönitzer [34] reported antibodies in $1-2 \%$ of formerly transfused patients. Secondly, these incidences were collected from a heterogeneous hospital 
patient population including multitransfused patients e.g. from the hematology/oncology or nephrology departments. Such patients on the other hand had never been candidates for PABD. Thirdly, a vast number of PABD patients will never be transfused (waste rates of up to $50 \%$ of the PABD) perioperatively or, even if transfused, will not have to undergo further planned surgical procedures with a high risk of intra- or postoperative transfusion again in their lifetime. Therefore, even if alloimmunization took place in these often old patients, which certainly has to be diagnosed, documented and disclosed to the patient, including the issuing of an emergency card, the patient is not at risk as long as no further transfusions become necessary.

In conclusion, in rare cases of preexisting red cell alloimmunization and complex antibodies of clinical relevance or in patients with a different ethnic background, who might get immunized against common red cell antigens, PABD in nonurgent surgery is a valid and important option. However, most of the patients who donate autologous RBCC preoperatively, have no or only miniscule potential benefits while they simultaneously undergo relevant risks as discussed above.

\section{Assumption 7: No Additional Logistic Expenditure and Low Costs}

For the patient, PABD poses high additional logistic efforts for extra-appointments including extra-traveling and extraphlebotomies, with the above discussed increased risk due to the blood donation process especially in older patients.

Depending on the infrastructure of the hospital and blood bank and on the responsibility for PABD shared between these two institutions, additional logistics are required in both. In the hospital, GMP must be implemented according to the law. Manufacturing license, additional production facilities, IT and quality management systems, a qualified person, additional well trained personnel, documentation systems, internal and external audits as well as extra (refrigerator) storage capacity are only some of the important prerequisites.

For the blood bank, mostly dealing with young healthy volunteers, older PABD patients means additional emergency requirements and training of the staff in view of the almost 12 times higher rate of VSOs or adverse events during or after donation [23]. Additional appointments, extra-medical history and more intense examination focused on the above mentioned higher risk of concomitant diseases, drug intake and procedures performed in the PABD patients, additional testing, extra-labeling as well as storage and transportation of the final blood products are some of the reasons for an increased logistic expenditure as well as for higher costs in the blood donor service center. There is a relative chance of cost-effectiveness only if these high expenses face a high throughput of PABD procedures per year. Small hospitals with low numbers of PABD procedures per year will never be able to reach an

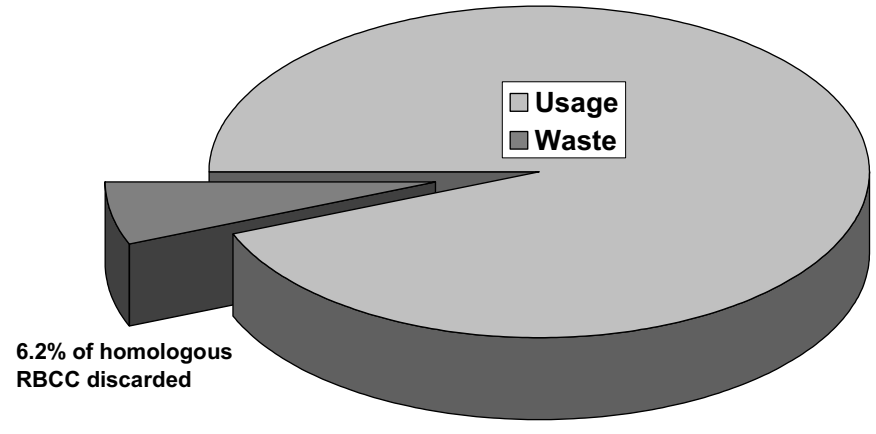

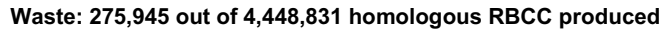

Fig. 5. Production data for homologous RBCC in Germany in 2002: Numbers and percentage of used and wasted products out of the blood bags produced [adapted from 2].

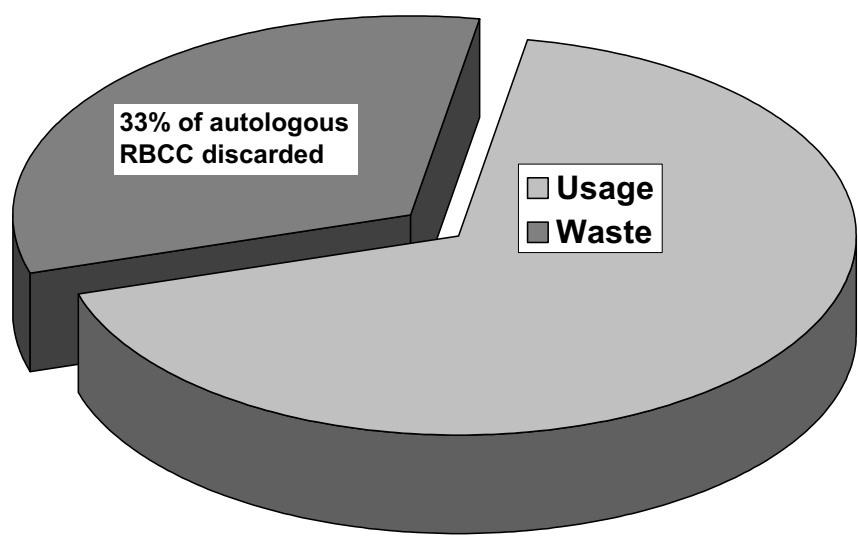

Waste: 53,670 out of 164,985 autologous RBCC produced

Fig. 6. PABD in Germany 2002: Production data for autologous RBCC. Numbers and percentage of used and wasted products out of the blood bags produced [adapted from 2].

acceptable cost-benefit ratio given the high additional personnel and logistic expenses.

In addition to the increased logistics and costs, the indication for and the information of the patient regarding PABD is given if the probability for transfusion reaches or exceeds $10 \%$ (see 'Introduction'). Therefore, theoretically up to $90 \%$ of the PABD products might be wasted. In real life, approximately one half of all PABD units collected in the USA are never transfused and are discarded [35].

In Germany, published data $[1,2]$ of the PEI shows a 5 times higher disposal rate for autologous RBCC (33\%) compared to homologous RBCC (6.2\%) in 2002. These results are depicted in figure 5 for homologous RBCC and in figure 6 for autologous RBCC.

Additional costs for PABD result from a higher rate of serious adverse events requiring hospitalization because of donationrelated complications in the older PABD patients as discussed 
above or due to transfusion of PABD products not being indicated ('over-transfusion').

Cost-effectiveness studies for PABD are regularly published [36, review in 35]. These studies often use costs per quality-adjusted life year (QALY) gained as a parameter to measure effectiveness of a medical procedure. Medical interventions are considered effective at about or less than EUR 50,000.- per QALY gained. QALY is a measure of the additional life years available to a person adjusted by the quality of health during those additional years.

The costs per QALY gained for PABD are tremendous due to the high waste of products, the low requirement for transfusion in some surgical procedures, the low risk of HCV or HIV transmission by homologous blood products, and the relatively high risks of adverse events during or after the PABD procedure itself. Brecher et al. [35] sum up the published estimates of costs for a single PABD unit per QALY gained: total hip arthroplasty USD 235,000.- to 740,000.-, total knee arthroplasty USD $1,146,000 .-$ to $1,147,000 .-$, coronary artery bypass grafting USD 494,000.- to 508,000.-, transurethral resection of the prostate USD 1,358,000.-, prostatectomy USD 531,000.-, and hysterectomy USD 23,643,000.-. These costs per QALY gained do not justify the uncritical indication for PABD procedures.

In conclusion, high logistic efforts and tremendous costs in some indications make it necessary to restrict PABD to certain well defined indications which are rare at the moment.

\section{Assumption 8: Active Involvement of the Patient}

Although very much desirable, active involvement of the patient in the surgical procedure planned does not necessarily imply PABD. The high costs and the potential risks of PAPD make other forms of active involvement of the patient much more reasonable, e.g. diagnosis and treatment of the above discussed preoperative anemia.

\section{Conclusion}

PABD can be the adequate solution to a patient's problem before nonurgent surgery if there is a high $(>10 \%)$ probability of perioperative blood transfusion in this individual case and, at the same time, preexisting alloimmunization or a different ethnic background makes it difficult to supply this patient with compatible RBCC. In times of acute shortness of blood when nonurgent surgery might be rescheduled and delayed, and in cases of extreme angst-ridden patients fearing homologous blood transfusion, PABD can be considered in rare individual cases as well. Nevertheless, in all these cases, the patient must be eligible for PABD and the indication as well as potential contraindications have to weighted against each other in a thorough individual risk-benefit analysis. However, these are relatively rare cases.

Apart from these and few other situations, PABD in our opinion should not be used because of high costs and logistic effort, high wastage, considerable risks for the donor/patient and miniscule benefits as documented by immense costs per QALY gained.

PABD cannot significantly contribute to the blood supply.

If $\mathrm{PABD}$ procedures are used, the same strict guidelines must be applied for production and clinical use, indications and contraindications as well as transfusion triggers as those exercised in homologous transfusion medicine. Extra-care should be adopted in labeling and storage of autologous products because they can only be transfused to the donor. Donations with positive infection markers should not be stored but destroyed. Extremely rare exceptions to this rule are necessary in defined clinical situations.

PABD in error-free use, which is unrealistic, reduces the risk of transmission of known and unknown viral pathogens but possibly not of bacteria. Currently, the vCJD transmission risk by blood transfusion seems to be minimal; considering the more clinically relevant risks such as clerical errors or bacterial contamination, this risk therefore is not an indication for PABD at the moment. New developments and insights might change this recommendation.

In real life situations, the residual risk for transmission of transfusion-relevant viruses, e.g. HIV, HVC or HBV, is not diminished by PABD. The same is true for clerical errors and $\mathrm{ABO}$ incompatibility or acute hemolytic transfusion reactions due to a mix-up of products.

PABD reduces the risk of (allo)immunization and therefore has its indication in special clinical situations.

PABD on the other hand increases the risk for the donor at the time of donation and afterwards. Autologous blood products seem to have higher rates of bacterial contamination. The risk for the patient to receive any transfusion perioperatively is increased due to the lower hemoglobin levels at admission (iatrogenic anemia) as well as due to a more liberal transfusion strategy in PABD procedures. Occasionally, transfusion triggers for autologous blood products are still erroneously different from homologous transfusion triggers.

Finally, the high costs of PABD compared to homologous blood products cannot be disregarded in times of financial shortages in the health care systems.

Improvements to the current PABD situation should be implemented by applying identical standards for production, testing, declaration, labeling, storage and transportation as well as indication and transfusion triggers for both autologous and homologous blood products.

A significant number of patients who would never receive any transfusion perioperatively at all enter the transfusion chain due to PABD procedures, facing the risks of a blood donor as well as the risks of a transfusion recipient. 


\section{References}

1 Bekanntmachung des Paul-Ehrlich-Institutes: Bericht zur Meldung nach $\$ 21$ für die Jahre 1999 und 2000. Bundesgesundheitsbl Gesundheitsforsch Gesundheitsschutz 2003;46:1016-1032.

- Haschberger B, Waterkamp A, Heiden M, Seitz R: Bericht zur Meldung nach \$21 TFG für die Jahre 2001 und 2002. Bundesgesundheitsbl Gesundheitsforsch Gesundheitsschutz 2005;48:99-119.

3 Mitteilungen des Arbeitskreises Blut: Aktuelle Empfehlungen zur autologen Hämotherapie (Votum, V32). Bundesgesundheitsbl GesundheitsforschGesundheitsschutz 2005;48:700-702.

4 Mercuriali F, Inghilleri G, Colotti MT, Farè M, Vinci A, Podico M, Scalamogna R: Bedside transfusion errors: analysis of 2 years' use of a system to monitor and prevent transfusion errors. Vox Sang 1996;70:16-20.

5 Goldman M, Rémy-Prince S, Trépanier A, Décary F: Autologous donation error rates in Canada. Transfusion 1997;37:523-527.

$\checkmark 6$ Domen RE: Adverse reactions associated with autologous blood transfusion: evaluation and incidence at a large academic hospital. Transfusion 1998;38:296-300.

7 Linden JV: Errors in transfusion medicine - scope of the problem. Arch Pathol Lab Med 1999;123: 563-565.

8 Shulman IA, Lohr K, Derdiarian AK, Picukaric JM: Monitoring transfusionist practices: a strategy for improving transfusion safety. Transfusion 1994; 34:11-15.

9 Caspari G, Alpen U, Greinacher A: Transfusion to the wrong patient likely to be the most important transfusion risk. Infus Ther Transfus Med 2001;28 (suppl 1):67.

10 Caspari G, Alpen U, Greinacher A: The risk of transfusion to the wrong patient in Germany. Transfusion 2002;42:1238-1239.

11 Mueller MM, Sireis W, Roth WK, Findhammer S, Seifried E: Preoperative autologous blood donation in Germany: is it worth the costs? - is it worth the risks? Transfus Med Hemother 2004;31(suppl 3):38.

12 Bundesärztekammer im Einvernehmen mit dem Paul-Ehrlich-Institut: Richtlinien zur Gewinnung von Blut und Blutbestandteilen und zur Anwendung von Blutprodukten (Hämotherapie). Aufgestellt gemäß Transfusionsgesetz - Gesamtnovelle 2005. Köln, Deutscher Ärzte-Verlag, 2006, Kapitel 2.8.1.3 (p 32).
13 Allain JP, Bianco C, Blajchman MA, Brecher ME, Busch M, Leiby D, Lin L, Stramer S: Protecting the blood supply from emerging pathogens: the role of pathogen inactivation. Transfus Med Rev 2005;19: 110-126.

14 Bundesärztekammer: Leitlinien zur Therapie mit Blutkomponenten und Plasmaderivaten, 3. Aufl. Köln Deutscher Ärzte-Verlag 2003, Kapitel 16 (p 259).

15 Woolhouse MEJ: Population biology of emerging and re-emerging pathogens. Trends Microbiol 2002; 10(suppl 10):S3-7.

16 Seifried E, Mueller MM: European Parliamentary public hearing on 'the impact of SARS and other emerging pathogens on transfusion medicine'. Blood Ther Med 2003;3:109-110.

17 Hunter N, Foster J, Chong A, McCutcheon S, Parnham D, Eaton S, MacKenzie C, Houston F: Transmission of prion diseases by blood transfusion. J Gen Virol 2002:83:2897-2905.

18 Llewelyn CA, Hewitt PE, Knight RSG, Amar K, Cousens S, Mackenzie J, Will RG: Possible transmission of variant Creutzfeldt-Jakob disease by blood transfusion. Lancet 2004;363:417-421.

19 Aguzzi A, Glatzel M: vCJD tissue distribution and transmission by transfusion - a worst-case scenario coming true? Lancet 2004;363:411-412.

20 Peden AH, Head MW, Ritchie DL, Bell JE, Ironside JW: Preclinical vCJD after blood transfusion in a PRNP codon 129 heterozygous patient. Lancet 2004;364:527-529.

21 Ludlam CA, Turner ML: Managing the risk of transmission of variant Creutzfeldt-Jakob disease by blood products. Br J Haematol 2005;132:13-24.

22 European Commission: Scientific committee on emerging and newly identified health risks (SCENIHR): opinion on the safety of human-derived products with regard to variant CreutzfeldtJakob disease. SCENIHR plenary meeting, September 28-29, 2005.

23 Popovsky MA, Whitaker B, Arnold NL: Severe outcomes of allogeneic and autologous blood donation: frequency and characterization. Transfusion 1995;35:734-737.

24 Davenport R: Nontransfusion hazards of autologous blood donation. Transfusion 2001; 41:152-153.

25 Henry DA, Carless PA, Moxey AJ, O'Connell D, Forgie MA, Wells PS, Fergusson D: Pre-operative autologous donation for minimising perioperative allogeneic blood transfusion (Cochrane Review); in: The Cochrane Library, Issue 4. Chichester, Wiley and Sons, 2004.
26 Forgie MA, Wells PS, Laupacis A, Fergusson D Preoperative autologous donation decreases allogeneic transfusion but increases exposure to all red blood cell transfusion: results of a meta-analysis. International Study of Perioperative Transfusion (ISPOT) investigators. Arch Intern Med 1998;158: 610-616.

27 Guralnik JM, Eisenstaedt RS, Ferrucci L, Klein HG, Woodman RC: Prevalence of anemia in persons 65 years and older in the United States: evidence for a high rate of unexplained anemia. Blood 2004;104:2263-2268.

28 Billote DB, Glisson SN, Green D, Wixson RL: A prospective, randomized study of preoperative autologous donation for hip replacement surgery. J Bone Joint Surg 2002;84A:1299-1304.

29 Müller U, Röder C, Pisan M, Orler R, El-Kerdi A, Eggli S: Autologous blood donation in total knee arthroplasties is not necessary. Acta Orthop Scand 2004;75:66-70.

30 Kanter MH, van Maanen D, Anders KH, Castro F, Mya WW, Clark K: Preoperative autologous blood donations before elective hysterectomy. JAMA 1996;276:798-801.

31 Mathews H, Klapper E, Pepkowitz S, Steele L, Goldfinger D: Preoperative deposit of autologous blood may be unnecessary to protect patients undergoing radical prostatectomy from allogeneic blood exposure. Transfusion 2001;41(suppl):54S.

32 Mathoulin-Pelissier S, Salmi LR, Huet C: Determinants of allogeneic transfusion among patients who had an autologous blood procedure, France. Eur J Epidemiol 2004;19:329-333.

33 Petz LD, Garratty G: Hemolytic transfusion reactions; in Petz LD, Garratty G (eds): Immune Hemolytic Anemias, 2nd ed. New York, Churchill Livingstone, 2004, pp 541-569.

34 Schönitzer D: Das Risiko der Antikörperbildung (Sensibilisierung des Empfängers) durch die Bluttransfusion; in Schönitzer D: Prätransfusionelle Untersuchungen, 2. Aufl. Basel, Karger, 1998, pp 122-133.

35 Brecher ME, Goodnough LT: The rise and fall of preoperative autologous blood donation. Transfusion 2002;42:1618-1622.

36 Etchason J, Petz L, Keeler E, Calhoun L, Kleinman S, Snider C, Fink A, Brook R: The cost effectiveness of preoperative autologous blood donations. $\mathrm{N}$ Engl J Med 1995;332:719-724. 